\title{
Comparison of Climatic Factors Contributing to Hand-Foot-and-Mouth Disease Outbreak in the Northern and the Central Regions of Thailand
}

\author{
Chomchid Phromsin ${ }^{1}$, Matrini Ruktanonchai ${ }^{1} \&$ Jitlada Phupijit $^{2}$ \\ ${ }^{1}$ Department of Geography, Faculty of Social Sciences, Kasetsart University, Thailand \\ ${ }^{2}$ Department of Environmental Science, Faculty of Environment, Kasetsart University, Thailand \\ Correspondence: Chomchid Phromsin, Department of Geography, Faculty of Social Sciences, Kasetsart \\ University, Thailand. Tel: 6-683-050-1029. E-mail: fsoccci@ku.ac.th
}

\author{
Received: August 24, 2020 Accepted: October 10, 2020 Online Published: October 23, 2020 \\ doi:10.5539/gjhs.v12n12p91 URL: https://doi.org/10.5539/gjhs.v12n12p91
}

\begin{abstract}
Background: Hand-foot-and-mouth disease (HFMD) has been noted as one of the most common contagious diseases in Thailand. Each year the highest reported cases have been mostly found in the Northern and the Central regions. These regions are quite different in terms of topography and climate. Therefore, the interest of this research was to compare the climatic factors that affect the incidence of HFMD outbreak.
\end{abstract}

Objective: The research objective was to identify the climatic factors influencing HFMD in the two regions.

Methods: The research applied spatial autocorrelation via the stepwise regression analysis to elaborate the influence of climatic factors on HFMD outbreaks during 2006-2016.

Results: The HFMD distribution patterns mapping in this study indicated that there were large infectious areas in almost every province in both the Northern and the Central regions during 2012-2016. The stepwise regression analysis evaluated all possible combinations of the explanatory input candidate variables, including average temperature, average rainfall, air pressure, and relative humidity. The study finds found that the major climate factors pertaining to HFMD occurrence in the Northern region were temperature and humidity $\left(\mathrm{R}^{2}=0.56\right)$, whereas humidity and rainfall $\left(\mathrm{R}^{2}=0.49\right)$ played important roles in the Central region. The results confirmed the meteorological factors which were statistically significant in association with HFMD cases in seasonal of Thailand.

Conclusion: It was concluded that the use of spatial autocorrelation in GIS and stepwise regression approach should be encouraged in epidemiology in estimating the involvement of meteorological indicators on the spatial distribution of HFMD and health geography in climate change situation.

Keywords: climate factors, hand-foot-and-mouth disease, Thailand

\section{Introduction}

Hand-foot-and-mouth disease (HFMD) was noted as a highly common and communicable infectious disease caused by viruses from the genus Enterovirus, mainly the enterovirus 71 also known as EV71 and most commonly the coxsackievirus A16 (CA16) (Jonathan et al., 2017). However, the most serious disease-causing strain was EV71, which was mainly found in Southeast Asia where Thailand is located. These viruses can spread among peopple through contaminated surfaces or by direct touching of contaminated hands. The contact with stool or saliva of an infected person can also cause transmission of the disease. Although HFMD occured mostly in infants and children, it can also be found in adults (Chen, 2019). Individual cases and outbreaks of HFMD have occured worldwide and particularly in tropical and subtropical countries where outbreaks often occured throughout the year. Outbreaks of HFMD occured every other years in different parts of the world, but in recent years these have occurred more frequently in Asia (Rastogi, 2016; Chan, 2015). Similar to other countries in Southeast Asia, Thailand was considered one of Asian countries having significantly high number of reported HFMD cases (Samphutthanon et al., 2014).

Thailand was indicated as one of the countries having high epidemic rate, mostly in children under the age of five (Suandork, 2019). The Bureau of Information office of the permanent Secretary of MOPH (2019) reported 
that most HFMD cases in Thailand were found in children under one-year old, followed by two and three-year old, respectively. These children spent much of their time in day cares, child development centers and kindergartens. Resulted by the urbanization and westernization processes in Thailand in recent years; nuclear families have replaced extended families in the Thai society so that young working parents had limited access to assistance from grandparents. Working parents increasingly needed to send their young children; mostly under three years of age, to daycare services or nurseries. This might be the cause for high epidemic rate of HFMD among Thai children. Moreover, the outbreak of this disease continuously disrupted the children's learning ability. To this regard, there was a policy for school administrators to announce school closing for at least 7-10 days if more than five students were detected as HFMD infected. This was in order to decontaminate service areas of the school and to stop further infections. Although little interest on health issues has been paid to HFMD, increasing concerns were captured due to the direct economic and social impacts at household level at large (Samphutthanon et al., 201).

With this regard, studies about epidemic were necessary. To obtain an understanding on the diffusion pattern of outbreaks, health geographers concentrated on the relationships between health cases and ecological processes, known as landscape ecology. Landscape ecology is the the examination of spatial patterns and their connection to ecological processes. Nowadays, geographic information system (GIS) and spatial analysis techniques were applied as decision making tools in the studies on epidemiology using landscape ecological approach. In a closer look to the use of GIS and patial analysis technuques, Jeefoo (2011) noted that the area of health GIS provided a strong framework for the increasing ability to monitor the diseases and identify their causes. This was because GIS mapping techniques had strong influences on the studies of public health, space-time mapping components, and the future of the discipline supported by Big Data.

In the past decades, several studies have revealed that climate changes have resulted in the changes of global environments in various ways. Liu et al. (2015) noted the need for investigations on the association between climatic variability and infectious diseases and highlighted the increasing substantiation of rapid global climatic change. Not only the notion of the urgent need to investigate the relationship between climatic variables and infectious diseases in general, but also HFMD in particular. Numbers of studies were conducted to explore the linkages between HFMD and spatial-temporal patterns. Liu (2013) and Chan (2015) highlighted the impacts of meteorological factors on HFMD. Moreover, the direct or indirect effects of weather variables in the transmission of HFMD were also considered. Another technique of spatial autocorrelation that measureed the correlation of a variable with itself through space was the Moran's I that can possibly be applied for the detection of epidemic clusters. For example, Liu (2013) constructed the spatio-temporal database of HFMD from 2007 to 2011 based on the National Disease Surveillance Reporting and Management System of China. Moreover, Chao Song (2018) explored several weather determinants such as average temperature, monthly precipitation, and average relative humidity to study the possible spatial variations in the incidence of HFMD due to these meteorological factors. Whereas Song and et al. (2018) found that the relationship between geographical factors and HFMD incidence were important factors to control and prevent HFMD outbreak and epidemic in China. Therefore, understanding the relationship between such variability and infectious disease occurrence was proved useful.

In general, climatic variability usually had strong impact on large-size countries. In case of Thailand; although it is a medium-sized country, climatic variability among different regions should be considered as the focus of epidemic of desiases, especially HFMD. This is because each region has diverse geographic characteristics such as topography, distance from water causes and distance from the equator that influenced on humidity, precipitation, temperature, and air pressure. As Upala (2018) found that the highest reported cases of HFMD each year were mostly found in the North and the Central regions.

The focus of this study was therefore to identify how the climatic factors have influenced HFMD in the Northern and the Central regions of Thailand. The study used the distribution pattern of HFMD patients reported during 2006 to 2016 in these regions to explain the relationship between climatic variables with HFMD outbreak. As well as applying the spatial autocorrelation and Moran's I in GIS to detect the clustering areas of HFMD patients' distribution.

\section{Material and Methods}

\subsection{Study Area and Data}

\subsubsection{Study Area}

The case study focused on the Northern and Central regions of Thailand - the regions with the highest HFMD 
infection rate in the country from 2006 to 2016 . The Northern region covers about $169,600 \mathrm{sq} . \mathrm{km}$, comprising 17 provinces whereas the Central region is about $91,798 \mathrm{sq}$. $\mathrm{km}$. with 18 provinces. This study employed the regions classified by the Thai Meteorological Department (Figure 1).

Thailand's Northern region is dominated by mountainous terrain. On the other hand, the Central region is the lowland of the Central Plain drained by the Chao Phraya River. Thailand's area is approximately 513,120 sq. $\mathrm{km}$., the different terrain does have impacts on regional climate as well.

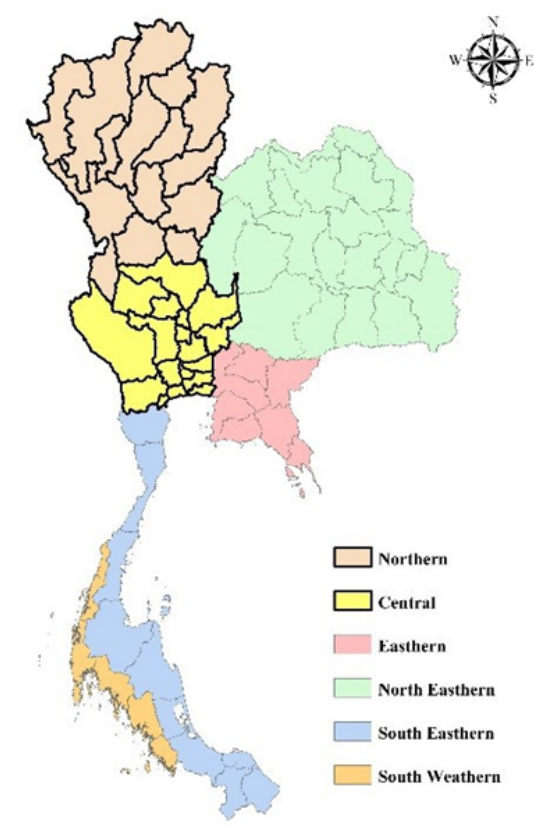

Figure 1. Study area; Northern and Central parts of Thailand

Thailand's climate is influenced by the monsoon: southwest monsoon, which normally lasts from mid-May to mid-October, called "the rainy season" inThailand, which brings rain and prevails over almost the entire country. The northeast monsoon, which lasts from mid-October to mid-February is called the "cool season" and brings with it dry weather with mild temperatures, particularly in the Northern region where the average temperature is much lower than the Central region. The pre-monsoon season, or "the hot season", runs from mid-February until mid-May and is characterized by higher temperatures in both regions.

\subsubsection{Meteorological Data}

Meteorological factors being investigated in this study included relative humidity, precipitation, mean temperature, maximum temperature, minimum temperature, and atmospheric pressure. The eleven years of monthly meteorological data, during 2006-2016, were derived data from meteorological stations by The Thai Meteorological Department. Then, the meteorological data from 120 point locations over the whole of Thailand was interpolated a raster surface by using inverse distance weighted technique in GIS. The data showed that average annual of humidity was 83.39 percent, average annual of rainfall was $132 \mathrm{~mm}$, average annual of temperature was 29.73 degree celsius and the atmospheric pressure was $1013.72 \mathrm{hPa}$. 


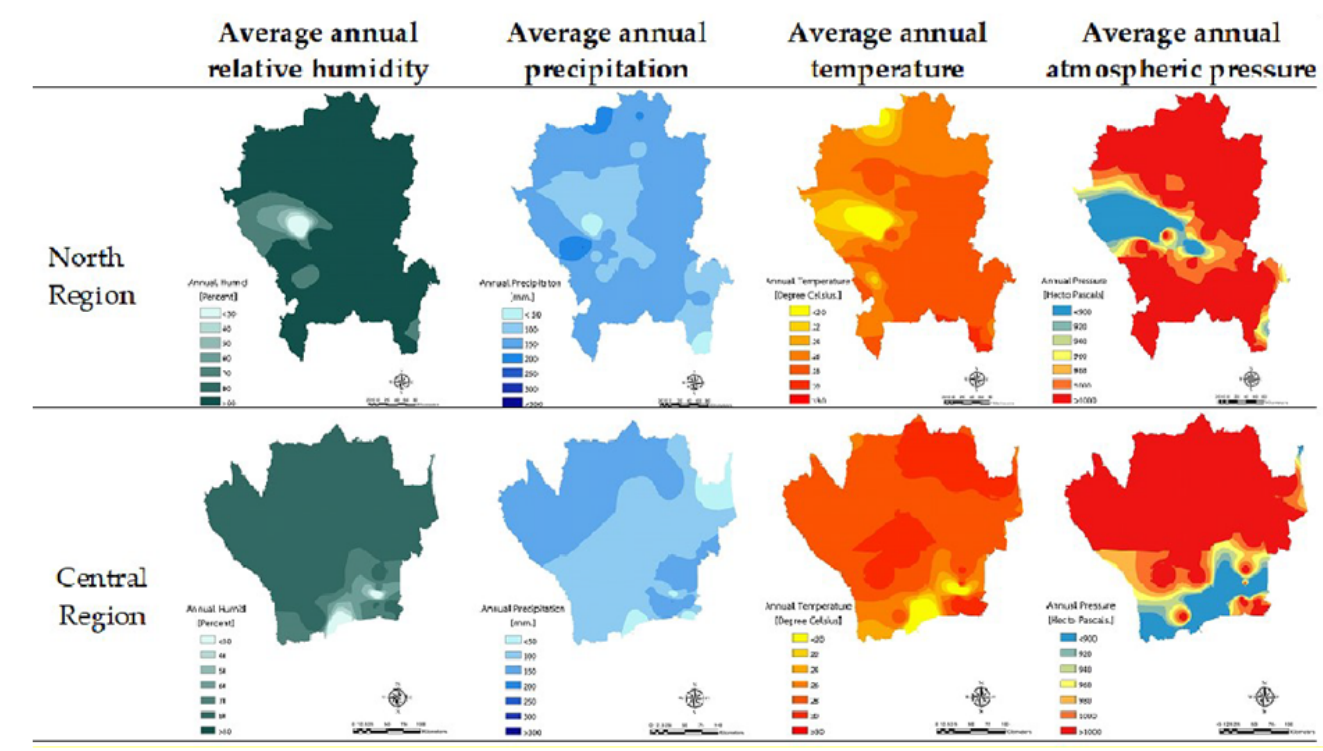

Figure 2. Eleven-year average meteorological data of the Northern and the Central regions of Thailand

Figure 2, the upper row maps displayed average relative humidity, precipitation, temperature, and atmospheric pressure per annual of the Northern region. The lower row displayed the same data for the Central region. The range of average relative humidity in this area was 30 to 60 percent per year. The average rainfall in this area was between 50 to $300 \mathrm{~mm}$ per year. The average temperature in this area was between 20 to 30 degree celsius per year and the average annual atmospheric pressure in this area was between 900 to $1,000 \mathrm{hPa}$.

\subsubsection{HFMD Data}

HFMD cases data during 2006-2016 were from Thailand's Department of Disease Control (2017). The HFMD incidence adopted in this study was the annual average value during the 11-year period. Average HFMD cases in Northern region was 5,258 cases and average cases in Central region was 7,856 cases.

\subsection{Statistical Models}

This research analyzed the distribution of cases by applying the spatial statistics. The data were processed through GIS to display qualitative characteristics in each area. The geographic information indicated the location and area of each province in the North and the Central regions of Thailand. The data were gathered and divided into two groups, namely the attribute data that consisted of HFMD cases during 2006-2016 at the district level together with the spatial data in presented in a digital map form that consisted of administrative divisions in the North and the Central regions.

\subsubsection{Spatial Autocorrelation and Moran's I in GIS}

One tool to measure spatial autocorrelation in GIS was the Global Moran's I. It can be applied for continuous data, based on feature locations and feature values concurrently. Jiang et al. (2017) noted that Moran's I help researchers to understand the degree to which one object was similar to other nearby objects. With a set of specific features and their associated attributes, Moran's I can evaluate whether the existing pattern is dispersed, random, or clustered. Once the Moran's I Index is computed, it provides both the z-score and p-value that can express the significance of the Index.

Spatial autocorrelation through global Moran I was applied in this study to analyze the trends for the annual number of HFMD cases at the district level. The index, signifying the clustering of data in some areas in this study, was calculated in GIS software with the following equation:

$$
I=\frac{n \sum_{i} \sum_{j} w_{i j}\left(x_{i}-\bar{x}\right)\left(x_{j}-\bar{x}\right)}{s_{0} \sum_{i}\left(x_{i}-x\right)^{2}}
$$

where;

$$
\begin{array}{cll}
\mathrm{I} & = & \text { the global Moran I index } \\
\mathrm{W}_{\mathrm{i}, \mathrm{j}} & = & \text { the weighted distance between districts } \mathrm{i} \text { and } \mathrm{j}
\end{array}
$$




$\begin{array}{lll}\mathrm{x}_{\mathrm{i}} & = & \text { the number of patients in district } \mathrm{i} \\ \mathrm{x}_{\mathrm{j}} & = & \text { the number of patients in district } \mathrm{j} \\ \bar{x} & = & \text { the average number of patients in each district } \\ \mathrm{n} & = & \text { the total number of districts }\end{array}$

The values of Moran's I range from -1 to +1 that can indicate if there is clustering or dispersion in a map. While a positive Moran's I hints that the data are clustered $(+1$ is perfect clustering of similar values), a negative Moran's I implies that the data are dispersed (-1 is perfect dispersion) (Jiang et al., 2017).

Spatial autocorrelation is important because statistics rely on observations that are independent from one another. If spatial autocorrelation exists in a map, then this goes against the assumption in statistics that observations are independent from each other. Another possible use of spatial autocorrelation is for the clustering and dispersion of disease analytics. Such trends can be better studied with the use of spatial autocorrelation analysis.

\subsubsection{Stepwise Regression}

Stepwise; also known as variable selection in machine learning, is a family of methods for adding or removing variables from a model sequentially. Stepwise Regression analysis evaluates all possible combinations of the input candidate explanatory variables. It is a data mining tool that will try all possible combinations of explanatory variables to see which models pass all of the necessary Ordinary Least Squares; OLS diagnostics. By evaluating all possible combinations of the candidate explanatory variables, this method greatly increase chances of finding the best model to solve problems or answer questions.

Choose a model by AIC in a Stepwise algorithm. A bias-corrected version of Akaike's Information Criterion called AICc was developed by Hurvich and Tsai in the year 1989. When the number of predictors far outnumbers the sample size, AICc is preferred. An intrinsic ordering among the values of all other criteria measures is observed. (Poh \& Mark, 2007)

This study utilized the stepwise method to select independent variables for the equation, namely the meteorological data consisting of temperatures, humidity, rainfall, and atmospheric pressure. The meteorological variable that correlated the most with the number of patients was entered into the equation first and tested for its statistical significance. If no significance could be established, then the variable was discarded. However, if significance could be established, the next variable was entered. Each time that the new meteorological variable was entered, all other independent variables in the equation were tested first. This was in order to see whether they should remain in the equation. If not, then they would be discarded. In such a case, the next correlated variable will be selected and entered into the equation. The selection and testing of variables continued until there was no other variable that could be entered into the equation or taken out of the equation. Then and only then, the selection will be over. At the end, the variable that was highly correlated with the number of patients was identified.

\section{Results}

\subsection{The Spatial Distribution of HFMD}

This study indicated cumulative number of HFMD cases in the Northern region was 72,835 cases (total 11 years) which the highest year was 2016 (14,992 cases). On the other hand, cumulative number of HFMD cases in Central region there were 108,778 cases (total 11 years) and the highest years was 2016 with 22,358 cases.

Figure 3 showed the resultant GIS mapping of the distribution of hand-foot-and-mouth disease patients per provinces. The difference of the incident rate was shown in shading from dark read to white color; the darker the color was, the higher the incident rate would be. In the Northern region of Thailand, the highest concentration of cases was the year 2016 with 14,992 cases and the lowest number of cases was the year 2007 with 882 cases. During 2014-2016 (13,760 8,117 and 14,992 HFMD cases respectively), the HFMD cases had clustered around neighboring areas in Chiang Rai Province (Amphoe Mueang Chiang Rai District), Phayao Province (Dok Khamtai District, Amphoe Mueang Phayao District, and Chun District) and Nan Province (Mae Charim District). These provinces are mountainous where most of the villages were mainly found in the valleys. 


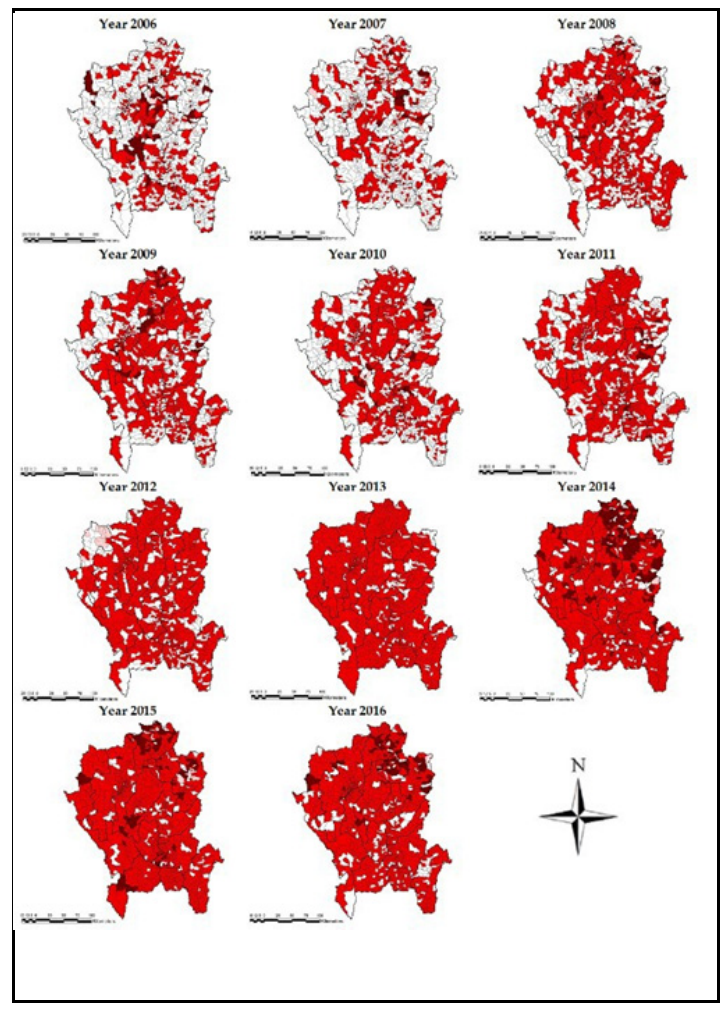

(a)

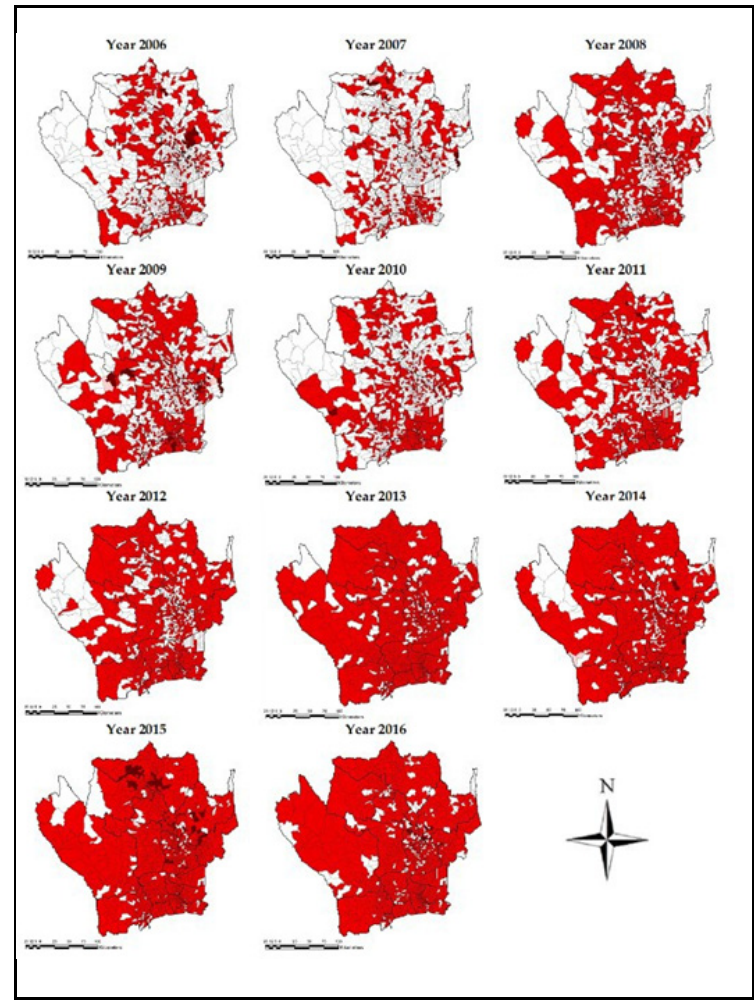

(b)

Figure 3. Spatial Distribution of HFMD Patients in the Northern region of Thailand (a) and Central region of Thailand (b) at the Amphoe, or, district level, during 2006-2016

In the Central region of Thailand, highest cases was 22,358 cases in the year 2016 and the lowest number of cases was the year 2007 with 1798 cases. During 2014-2016 (21,552 12,135 and 22,358 HFMD cases respectively). The highest concentration of cases were found in Bangkok, Nakhon Sawan Province (Amphoe Mueang Nakhon Sawan District) and in Phra Nakhon Si Ayutthaya Province (Nakhon Luang District) respectively. Year 2016 was the highest HFMD cases in this region, 8,227 HFMD cases was in Bangkok, 1,777 HFMD cases was in Nakhon Sawan province and 787 cases in Nakhon Si Ayutthaya province. Bangkok is the capital and the most populous city of Thailand with about 8 million people and Nakhon Sawan and Phra Nakhon Si Ayutthaya provinces accommodated large urban areas of the Central Plain of Thailand as well. In the same year Nakhon Sawan Province had about 1 million people whereas Phra Nakhon Si Ayutthaya's population is around 800,000 people that were about $4.0 \%$ and $5.3 \%$ of total population of the central region in the same year. The morphology of central region is a floodplain and a lowland area drained by the Chao Phraya River.

\subsection{Spatial Autocorrelation and Moran's I}

In order to conclude whether the disease was spatially clustered, dispersed, or randomly distributed, this study used Moran's I spatial autocorrelation. The tool evaluated the significance of Moran's I index with the generation of Z-score and p-value. The critical values (Z-scores) presented a likelihood of the clustered pattern being caused by random chance as follows - a Z-score between 1.65-1.96 presented a 10 percent likelihood, a Z-score between 1.96-2.58 present a 5 percent likelihood, and Z-score greater than 2.58 presented a 1 percent likelihood The z-score was between 1.65-1.65 meaning that the pattern appeared not to be significantly different than random.

The results of the spatial autocorrelation tests were listed in Table 1 which the values of Moran's I range from -1 to $+1 ;+1$ is perfect clustering and -1 is perfect dispersion. The table showed that elevated global spatial autocorrelation of HFMD existed at the Amphoe or district level within each epidemic year during 2006-2016. A higher than zero value of Moran's I or cluster pattern was observed for almost every year. In the North, the index of every year exhibited different levels of clustering. In 2016 the highest values were found for both the Moran's I and Z scores ( 0.735 and 6.260, respectively) or most cluster of HFMD cases in this year, followed by 2007 ( 0.020 and 6.165 , respectively). Similarly, the index of the year 2016 also had the highest values for Central 
Thailand for both the Moran's I and Z scores ( 0.381 and 64.53 , respectively). However, such result indicateed that the pattern was much more clustered on the plain of Central Thailand is higher than in mountainous areas or the North region of Thailand. For the central region, the majority of clustering pattern was found much more than it was found in the North, particularly during 2007-2011 and 2014-2016 that was $72.73 \%$ of the years studied. On the other hand, the North exhibited clustering pattern in 2006-2009 and 2016 that was $45.45 \%$ of the years studied. Such results should be useful for epidemic control in the future.

Table 1. Spatial autocorrelation analyses (Moran's I) for annualized incidence of HFMD in terms of patient cases per unit population in Central and Northern regions during 2006 to 2016

\begin{tabular}{lllllll}
\hline \multirow{2}{*}{ Year } & Northern region & \multicolumn{3}{c}{ Central region } \\
\cline { 2 - 7 } & Moran's I & $\mathbf{Z}$ & P-Value & Moran's I & $\mathbf{Z}$ & P-Value \\
\hline 2006 & 0.004 & 3.212 & 0.001 & 0.006 & 1.628 & 0.103 \\
2007 & 0.020 & 6.165 & 0.000 & 0.057 & 11.328 & 0.000 \\
2008 & 0.000 & 0.642 & 0.001 & 0.046 & 2.640 & 0.000 \\
2009 & 0.004 & 2.990 & 0.002 & 0.263 & 42.855 & 0.000 \\
2010 & 0.000 & 1.232 & 0.217 & 0.062 & 10.266 & 0.000 \\
2011 & 0.000 & 0.732 & 0.464 & 0.038 & 6.364 & 0.000 \\
2012 & 0.000 & 0.128 & 0.898 & 0.000 & 0.700 & 0.479 \\
2013 & 0.000 & 0.609 & 0.542 & 0.000 & 1.117 & 0.263 \\
2014 & 0.001 & 0.736 & 0.461 & 0.275 & 46.837 & 0.000 \\
2015 & 0.001 & 1.231 & 0.218 & 0.084 & 14.968 & 0.000 \\
2016 & 0.735 & 6.260 & 0.000 & 0.381 & 64.583 & 0.000 \\
\hline
\end{tabular}

\subsection{Influenceing Climate factors of Hand-Foot-and-Mouth Disease}

Several previous studies indicated an association between incidents of HFMD and weather factors (Samphutthanon et al., 2014). Furthermore, the outbreak of HFMD tended to relate to the seasonal changes that were resulted by the changes of temperature, rainfall, air pressure, and relative humidity. Therefore, the study used these 4 factors as the influential variables in analyzing the relationship between climatic factors and the HFMD outbreak in the northeastern and eastern regions. To analyze, the study applied stepwise regression analysis method that focused on the R2 adjusted (R2ADJ).

The stepwise regression analysis evaluated all possible combinations of the input candidate explanatory variables, including the average temperature, average rainfall, air pressure, and relative humidity. The study found that 3 of 4 or all 4 climate variables not separate the different influence of two areas to HDMD. However, that were 2 of 4 variables of both study sites are better than others. The climate factors effected to HFMD occurrence in central part of Thailand, the meteorological variables has influence this area is rainfall and humid variables $(\mathrm{R} 2=0.49)$ that can explain by season in this area. The temperature in this area there are not different in every seasons however, in rainy season, humidity was generally higher. Moreover the result showed that the rainfall variable was statistically significant with positive correlation. For Northern part of Thailand, the more significant factors were temperature and humid $(\mathrm{R} 2=0.56)$ - similar to the study of Samphutthanon et al. 2014 which found that most outbreaks occurred during the rainy and cold season in the north part of Thailand as shown in Table 2. 
Table 2. Comparing variable selection with stepwise; Northern and Central regions

\begin{tabular}{|c|c|c|c|c|c|c|c|}
\hline \multicolumn{4}{|l|}{ Central } & \multicolumn{4}{|l|}{ North } \\
\hline Variables & AICc1 & VIF2 & R2ADJ3 & Variables & AICc & VIF & R2ADJ \\
\hline 2 0f 4 Variables & & & & 2 of 4 Variables & & & \\
\hline Rain, Humid & 137.18 & 1.17 & 0.49 & Temp, Humid & 107.89 & 1.23 & 0.56 \\
\hline Rain, Temp & 137.83 & 1.06 & 0.47 & Rain, Humid & 108.55 & 1.25 & 0.53 \\
\hline Humid, Press & 138.69 & 1.12 & 0.44 & Humid, Press & 110.60 & 1.33 & 0.46 \\
\hline 3 0f 4 Variables & & & & 3 0f 4 Variables & & & \\
\hline Rain, Humid, Temp & 140.05 & 1.22 & 0.48 & Temp, Humid Rain, & 111.69 & 2.13 & 0.54 \\
\hline Rain, Humid, Press & 140.90 & 1.30 & 0.46 & Temp, Humid, Press & 112.00 & 2.02 & 0.54 \\
\hline Rain, Temp, Press & 141.67 & 1.22 & 0.43 & Rain, Humid, Press & 112.64 & 2.09 & 0.52 \\
\hline 4 0f 4 Variables & & & & 4 of 4 Variables & & & \\
\hline Temp,Rain, Humid, Press & 144.61 & 1.38 & 0.44 & Temp,Rain, Humid, Press & 117.65 & 2.28 & 0.52 \\
\hline
\end{tabular}

${ }^{1}$ Akaike's Information Criterion 2 Max Variance Inflation Factor 3 Adjusted R-Squared.

The research also found the correlation coefficients of HFMD patients with the climatic factors. It was shown that the factors correlated with the number of patients in the North were average temperature and relative humidity, and the climatic factors correlated with the number of patients in the central region were average rainfall and relative humidity.

As Leong (2011) found that HFMD did occur in temperate countries during summer season, but being occured throughout the year in tropical countries. The number of monthly HFMD cases in the study with different climatic factors indicated that HFMD did occur in 2 seasons. Cold temperature and low relative humidity or during the cool season (2nd semester of pre-school or primary school in Thailand) might have stimulated the increase of HFMD incidence in Northern Thailand. On the other hand, high rainfall and relative humidity or during the rainy season (1st semester of pre-school or primary school in Thailand) might have stimulated the increased HFMD incidence in Central Thailand.

\section{Discussion}

HFMD had recently become a significant health issue in Thailand. Most outbreaks occurred mainly in the Northern region and the Central region, respectively. When most health geographers studied about epidemiology they usually focused on cases and relationships between ecological processes in the environment or known as landscape ecology. Geographic information system, GIS, was applied as a promising tool in medical and health applications. This study applied the GIS to illustrate the distribution of HFMD patients between the years 2006-2016 at the district level of the Northern and the Central regions of Thailand. The scenario mapping helped researchers to understand the trend of disease epidemic throughout the regions. The distribution mapping in this study indicated that the Central region had a stronger trend to have re-emerging disease in the same area than the Northern region. There were large infectious areas, almost every province in both the Northern and the Central regions during 2014-2016. Moreover, the concentration or high incidence areas in the Northern region were found in Chiang Rai, Phayao, and Nan provinces in the years 2014-2016. For the Central region, the high incidence rate was found in Bangkok, Nakhon Sawan Province and in Phra Nakhon Si Ayutthaya Province in the same 3 years. Such results confirmed that HFMD was one of the most critical health issues in Thailand.

In addition, spatial autocorrelation analyses (Moran's I) though geographic information system indicated that the clustering epidemic in the Central region were found more often than that in the Northern region, particularly during 2007-2011 and 2014-2016. It was noticeable that the distribution was more of a cluster pattern on the plain of Central Thailand than in the mountainous areas of the North which concured with studies in China. (Jin-feng, 2011; Jiaojiao, 2014).

The study found that the climatic factors which were statistically and significantly associated with HFMD cases in the Northern Thailand were temperature and humidity. The two factors had more influence on the increased HFMD incidence during the cool season. The cool season was around the end of November to the end of February and the average temperature in this season period was approximately $23.3{ }^{\circ} \mathrm{C}$, that were closed to average temperature in summer season of temperate countries. This study indicated that rainfall and humidity of 
the Central region during the rainy season might have stimulated the increased HFMD incidence.

In the Central region, the data of the rainfall between the years 2006 to 2016 showed that Bangkok metropolis had the highest rainfall $(151.06 \mathrm{~mm} /$ year $)$ while Supanburi province had lowest level $(81.03 \mathrm{~mm} /$ year$)$. Futhermore, Nakhon Sawan province - located at the middle south of the Central part of Thailand - which has the high incident rate of rainfall that was $102.94 \mathrm{~mm} /$ year. Due to the morphology of Central region that is located in floodplain and in lowland area drained by the Chao Phraya River, and in the southern part of the region is closed to the gulf of Thailand; the south-west monsoon contributed to producing heavy rainfall more than the Northern region.

As noted in the literatures being reviewed, three climatic factors including temperature, rainfall, and humidity were statistically significantly associated with HFMD cases. As shown in previous studies from Asian countries, particularly China (Huang et al., 2013, Jiaojiao, 2017), Hong Kong (Wang, 2016), Japan (Onozuka \& Hashizume, 2011), and Singapore (Hii et al., 2011), this study also showed a positive association between the climatic factors and the HFMD outbreak - especially temperature and humidity. However, a difference was observed in case of the findings from the study in Guangzhou, China (Huang et al., 2013). This study showed a positive association between rainfall and HFMD cases and the sensitive effect to spatial and incident rate although in small area as Thailand whereas the case of Guangzhou, China found the opposite findings which probably was due to the differences of the size of the study area.

\section{Conclusion}

The results of this study showed that the most significant climatic factors that influced HFMD outbreak tended to be temperature and humidity in the Northern region, whereas rainfall and humidity were found most important in the Central region. The study results confirmed that the climatic factors were statistically associated with HFMD cases. However, it was possible that topography might also have significant effect on the pattern of disease distribution, especially in the areas with diverse topographies. It was recommended to utilize the findings of this study not only for formulating outbreak control, but also for predicting the possibilities of new epidemics or pandemics in these seasons. Moreover, using spatial autocorrelation and Moran's I in GIS and stepwise approach to estimate the contribution of climatic indicators on the spatial distribution of HFMD should be encouraged in epidemiology and health geography.

\section{Funding}

This research was financially supported by geography department and social sciences faculty, Kasetsart University for publishing.

\section{Acknowledgments}

The authors wish to acknowledge the Department of Disease Control Thailand for providing relevant data.

\section{Competing Interests Statement}

The authors declare that they have no known competing financial interests or personal relationships that could have appeared to influence the work reported in this paper.

\section{References}

Chen, Y., Lan, H., Feng, X., Cheng, L., \& Jing, L. (2019). A case report of a teenager with sever hand, foot and mouth disease with brainstem encephalitis caused by enterovirus 71. BMC Pediatrics, 19, 59. https://doi.org/10.1186/s12887-019-1428-4

Cox, A. J., Julian, A. H., Tom, S., \& Mong-How, O. (2017). Immunopathogenesis and Virus-Host Interactions of Enterovirus 71 in Patients with Hand, Foot and Mouth Disease. Fontiers in Microbiology, 8, 1-14. https://doi.org/10.3389/fmicb.2017.02249

Dube, J., \& Legros, D. (2014). Spatial Autocorrelation. Spatial Econometrics Using Microdata (pp. 59-91). ISTE Ltd and John Wiley \& Sons, Inc. https://doi.org/10.1002/9781119008651.ch3

Hii, Y. L., Rocklöv, J., \& Ng, N. (2011). Short Term Effects of Weather on Hand, Foot and Mouth Disease. PLoS One, 6(2), e16796. https://doi.org/10.1371/journal.pone.0016796

Huang, Y., Te, D., Shicheng, Y., Jing, G., Cunrui, H., Gexin, X., \& Yuantao, H. (2013). Effect of meteorological variables on the incidence of hand, foot, and mouth disease in children: a time-series analysis in Guangzhou, China. BMC Infect Dis., 13, 134. https://doi.org/10.1186/1471-2334-13-134

Jeefoo, P., Tripathi, N. K., \& Souris, M. (2011). Spatio-temporal diffusion pattern and hotspot detection of dengue in Chachoengsao province, Thailand. Int. J. Environ. Res Public Health, 8(1), 51-74 https://doi.org/10.3390/ijerph8010051 
Jiang, Y., Fan, F., Zanoni, I., \& Li, Y. (2017). Global diffusion pattern and hot spot analysis of vaccine preventable diseases. ISPRS Ann. Photogramm. Remote Sens. Spatial Inf. Sci., IV-4/W2, 167-173. https://doi.org/10.5194/isprs-annals-IV-4-W2-167-2017

Jiaojiao W., Cao, Z., Zeng, D. D., \& Wang, Q. (2017). Assessing local risk factors of Beijing Hand-Foot- Mouth Disease in China. Online J Public Health Inform, 9(1), e009. https://doi.org/10.5210/ojphi.v9i1.7759

Jiaojiao, W., Zhidong, C., Daniel, D. Z., Quanyi, W., Xiaoli, W., \& Haikun, Q. (2014). Epidemiological Analysis, Detection, and Comparison of Space-Time Patterns of Beijing Hand-Foot-Mouth Disease (2008-2012). PLoS ONE, 9(3), e92745. https://doi.org/10.1371/journal.pone.0092745

Jin-feng, W., Guo, Y. S., Christakos, G., Yang, W. Z., Liao, Y. L., Li, Z. J., ... \& Chen, H. Y. (2011). Hand, foot and mouth disease: spatiotemporal transmission and climate. International Journal of Health Geographics, 10, 25. https://doi.org/10.1186/1476-072X-10-25

Leong, P. F., Labadin, R. J., Rahman, A. B. S., \& Samson, J. S. F. (2011). Quantifying the relationship between the climate and hand-foot-mouth disease (HFMD) incidences. In Proceedings of Modeling Simulation and Applied Optimization (ICMSAO). 2011 4th International Conference, Universiti Malaysia Sarawak, Sarawak, Malaysia, April 2011. https://doi.org/10.1109/ICMSAO.2011.5775582

Liu, Y., Wang, X., Liu, Y., Sun, D., Ding, S., Zhang, B., Du, Z., \& Xue, F. (2013). Detecting spatial-temporal clusters of HFMD from 2007 to 2011 in Shandong Province, China. PubMed. Published online 2013 May 21. https://doi.org/10.1371/journal.pone.0063447

Liu, Y., Wang, X., Pang, W., Yuan, Z., Li, H., \& Xue, F. (2015). Spatio-temporal analysis of the relationshio between climate and hand, foot, and mouth disease in Shandong province, China, 2008-2012. BMC Infectious Diseases, 15, 146. https://doi.org/10.1186/s12879-015-0901-4

Onozuka, D., \& Masahiro, H. (2011). The influence of temperature and humidity on the incidence of hand, foot, and mouth disease in Japan. Sci Total Environ., 1, 410-411, 119-25. https://doi.org/10.1016/j.scitotenv.2011.09.055

Poh, C. L., \& Ann, S. H. M. (2007). GIS for Health and the Environment: Development in the Asia-Pacific Region. Springer Science \& Business Media, 77-121. https://doi.org/10.1007/978-3-540-71318-0

Rastogi, A. (2016). Hand, Foot and Mouth Disease. Retrieved 16 February, 2019, from https://www.nhp.gov.in/disease/communicable-disease/hand-foot-and-mouth-disease

Samphutthanon, R., Tripathi, N. K., Ninsawat, S., \& Duboz, R. (2014). Spa-Temporal Distribution and Hotspots of Hand, Foot and Mouth Disease (HFMD) in Northern Thailand. Int. J. Environ. Res Public Health, 11, 312-336. https://doi.org/10.3390/ijerph110100312

Song, C., He, Y., Bo, Y., Wang, J., Ren, Z., \& Yang, H. (2018). Risk Assessment and Mapping of Hand, Foot, and Mouth Disease at the County Level in Mainland China Using Spatiotemporal Zero-Inflated Bayesian Hierarchical Models. Int. J. Environ. Res Public Health, 15(7), 1476. https://doi.org/10.3390/ijerph15071476

Suandork, P. (2019). Hand, Foot and Mouth Disease and enterovirus 71. Retrived from http://www.pidst.or.th/A296.html

The Bureau of Information office of the permanent Secretary of MOPH. (2019). Hand, Foot and Mouth Disease. Retrived from https://pr.moph.go.th/?url=pr/detail/2/04/127436/

Upala, P., Apidechkul, T., Suttana, W., Kullawong, N., Tamornpark, R., \& Inta, R. (2018). Molecular epidemiology and clinical features of hand, foot and mouth disease in northern Thailand in 2016: a prospective cohort study. BMC Infectious Diseases, 18, 630. https://doi.org/10.1186/s12879-018-3560-4

Wang, P., Goggins, W. B., \& Chan, E. Y. Y. (2016). Hand, Foot and Mouth Disease in Hong Kong: A Time-Series Analysis on Its Relationship with Weather. PLoS One, 11(8), e0161006 https://doi.org/10.1371/journal.pone.0161006

\section{Copyrights}

Copyright for this article is retained by the author(s), with first publication rights granted to the journal.

This is an open-access article distributed under the terms and conditions of the Creative Commons Attribution license (http://creativecommons.org/licenses/by/4.0/). 